December 2004 - NREL/CP-500-39589

\title{
Development and Validation of an Aeroelastic Model of a Small Furling Wind Turbine
}

\section{Preprint}

J.M. Jonkman

National Renewable Energy Laboratory

A. Craig Hansen

Windward Engineering, LLC

To be presented at the $43^{\text {rd }}$ AIAA Aerospace Sciences Meeting and Expedition Reno, Nevada January 10-13, 2005
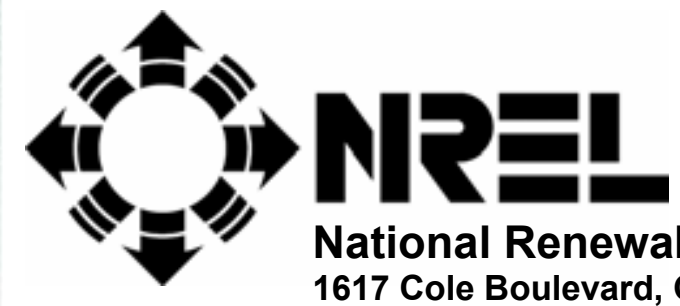

National Renewable Energy Laboratory 1617 Cole Boulevard, Golden, Colorado 80401-3393 303-275-3000 • www.nrel.gov

Operated for the U.S. Department of Energy

Office of Energy Efficiency and Renewable Energy

by Midwest Research Institute $\bullet$ Battelle

Contract No. DE-AC36-99-G010337 


\section{NOTICE}

The submitted manuscript has been offered by an employee of the Midwest Research Institute (MRI), a contractor of the US Government under Contract No. DE-AC36-99G010337. Accordingly, the US Government and MRI retain a nonexclusive royalty-free license to publish or reproduce the published form of this contribution, or allow others to do so, for US Government purposes.

This report was prepared as an account of work sponsored by an agency of the United States government. Neither the United States government nor any agency thereof, nor any of their employees, makes any warranty, express or implied, or assumes any legal liability or responsibility for the accuracy, completeness, or usefulness of any information, apparatus, product, or process disclosed, or represents that its use would not infringe privately owned rights. Reference herein to any specific commercial product, process, or service by trade name, trademark, manufacturer, or otherwise does not necessarily constitute or imply its endorsement, recommendation, or favoring by the United States government or any agency thereof. The views and opinions of authors expressed herein do not necessarily state or reflect those of the United States government or any agency thereof.

Available electronically at http://www.osti.gov/bridge

Available for a processing fee to U.S. Department of Energy and its contractors, in paper, from:

U.S. Department of Energy

Office of Scientific and Technical Information

P.O. Box 62

Oak Ridge, TN 37831-0062

phone: 865.576 .8401

fax: 865.576.5728

email: mailto:reports@adonis.osti.gov

Available for sale to the public, in paper, from:

U.S. Department of Commerce

National Technical Information Service

5285 Port Royal Road

Springfield, VA 22161

phone: 800.553 .6847

fax: 703.605.6900

email: orders@ntis.fedworld.gov

online ordering: http://www.ntis.gov/ordering.htm 


\title{
Development and Validation of an Aeroelastic Model of a Small Furling Wind Turbine
}

\author{
Jason M. Jonkman* \\ National Renewable Energy Laboratory (NREL), Golden, Colorado, 80401-3393 \\ and \\ Dr. A. Craig Hansen ${ }^{\dagger}$ \\ Windward Engineering LLC, Salt Lake City, Utah, 84117
}

\begin{abstract}
Small wind turbines often use some form of furling (yawing and/or tilting out of the wind) to protect against excessive power generation and rotor speeds in high winds. Though the apparatus used to passively furl a rotor is straightforward, the modeling of furling behavior is inherently complex, because the behavior depends on the rotor tilt angle and thrust offset, furling arrangement and mass balance and numerous other properties. Until recently, ADAMS ${ }^{\circledR}$ with AeroDyn has been the only simulator capable of modeling this complex aeroelastic furling problem. The need for a simulator with furling capability that is simpler to use and more readily available led NREL to upgrade their FAST aeroelastic simulator. The upgrade's features include a lateral offset and skew angle of the rotor shaft, rotor- and tail-furling degrees-of-freedom, up- and down-furl stops and tail fin aerodynamics and inertia. To verify and validate these new features, response comparisons were made between FAST, ADAMS and test data from the Small Wind Research Turbine. The verification study demonstrated the correct implementation of FAST's furling dynamics. During validation, the model tends to predict mean rotor speeds higher than measured in spite of the fact that the mean furl motion and rotor thrust are predicted quite accurately. This work has culminated with an enhanced version of FAST that should prove to be a valuable asset to designers of small wind turbines.
\end{abstract}

\section{Introduction}

S MALL distributed-scale wind turbines rated $50 \mathrm{~kW}$ or less often use some form of furling to protect the turbine against excessive power generation and rotor speeds in high winds. Furling is a passive form of control in which the rotor yaws and/or tilts out of the wind to limit the aerodynamic torque and thrust loading.

Furling control is impractical in large utility-scale wind turbines because of the enormous gyroscopic loads that would ensue. Instead, large wind turbines usually employ active controls to regulate power, limit loads and improve stability. These include active control of the blade pitch, generator torque and nacelle yaw. These means of control are unreasonable for small wind turbines due to the large costs involved.

Furling behavior is achieved through the use of a lateral rotor thrust offset, a tail fin and a furling hinge. In high winds, the rotor thrust and aerodynamic moments tend to yaw the rotor out of the wind. The furling hinge allows the tail to remain nominally aligned with the wind while the rotor yaws out of the wind.

Several furling hinge configurations have been used successfully in small commercial wind turbines. In one configuration, the tail boom is connected to the tower-top through the yaw bearing and the furling hinge is placed between the tail boom and the generator housing, which in turn connects to the rotor through the rotor bearing. This

\footnotetext{
* Engineer II-Structural Systems \& Dynamics, National Wind Technology Center (NWTC), 1617 Cole Boulevard, AIAA Professional Member.

${ }^{\dagger}$ Partner, 2225 East Murray-Holladay Road \#201A.
}

This material is declared a work of the U.S. Government and is not subject to copyright protection in the United States. 
configuration, which is employed in Southwest Windpower's Whisper H40 wind turbine (Fig. 1), is referred to as rotor-furling in this paper. In another configuration, the generator housing is connected to the tower-top through the yaw bearing and the furling hinge is placed between the generator housing and the tail boom. This configuration, which is employed in Bergey Windpower ${ }^{\S}$ s Excel wind turbine (Fig. 2), is referred to as tail-furling in this paper. Other furling configurations are possible, though less common, and are not discussed at length in this paper.

Though the apparatus used to passively furl a rotor is simple and straightforward, furling behavior is inherently complex because it is affected by the unsteady aerodynamics of a rotor in a highly skewed flow; rotor tilt angle and lateral thrust offset; furling hinge configuration and mass balance; tail size, location and lift and drag characteristics; blade pitch; alternator torque characteristics and numerous other properties. This complexity makes optimization difficult and provides incentive to use a comprehensive aeroelastic turbine simulator in the design process.

Over the past decade, the U.S. Department of Energy's (DOE's) National Renewable Energy Laboratory (NREL) ${ }^{* *}$ has sponsored the development, verification and validation of comprehensive aeroelastic simulators capable of predicting both the extreme and fatigue loads of horizontal-axis wind turbines (HAWTs). These simulation tools, also known as design codes, are used by industry, academia and government entities for wind turbine design, certification and research.

In general, these design codes enable a user to (1) define an aerodynamic and structural model of a wind turbine given the turbine geometry and aerodynamic and mechanical properties of its members and (2) simulate the wind turbine's aerodynamic and structural response by imposing complex, virtual, wind-inflow conditions. Outputs of the simulations include time-series data on the aerodynamic loads, as well as loads and deflections of the structural members of the wind turbine. Post-processing codes are then used to analyze these data.

FAST (Fatigue, Aerodynamics, Structures, and Turbulence) and ADAMS ${ }^{\circledR}$ (Automatic Dynamic Analysis of Mechanical Systems) ("ADAMS" is used to imply "ADAMS" ${ }^{\mathbb{B}}$ " throughout this paper) ${ }^{2,3}$ are two of the primary design codes used by the U.S. wind industry and the two most promoted by NREL's National Wind Technology Center (NWTC) ${ }^{\dagger \dagger}$. FAST is a relatively simple, structural-response, HAWT-specific code written and distributed by the NWTC. The code is based on previous developments done at Oregon State University and the University of Utah. The more complex ADAMS code is a commercially available, general purpose, multibody-dynamics code from MSC.Software Corporation that is adaptable for modeling wind turbines. Both FAST and ADAMS use the AeroDyn aerodynamic subroutine package developed by Windward Engineering LLC ${ }^{\S \S}$ for calculating aerodynamic forces.

Until recently, ADAMS with AeroDyn has been the only code capable of modeling the complex aeroelastic furling problem. This and the complexity and cost involved with using ADAMS, are some of the reasons why design refinement of small furling wind turbines has historically depended almost entirely on trial-and-error testing. For years, designers of small wind turbines have asked the NWTC to develop a simpler-to-use and more-readily available wind turbine simulator with furling capability. In fact, code development was a recommended action of the NWTC Furling Workshop held in July of $2000^{* * *}$.

To address these requests, the NWTC has recently upgraded their FAST code to include furling effects. This paper presents the results of this effort and shows comparisons of the new FAST model predictions to ADAMS

\footnotetext{
\$ Website: http://www.windenergy.com/.

$\S$ Website: http://www.bergey.com/.

${ }^{* *}$ Website: http://www.nrel.gov/.

† Website: http://www.nrel.gov/wind/.

\$ Website: http://www.mscsoftware.com/.

$\S \S$ Website: http://www.windwardengineering.com/.

${ }^{* * *}$ Website: http://wind.nrel.gov/Furling/workshop.html.
} 
model predictions and, more importantly, to test data taken from the NWTC's recent testing campaign of the Small Wind Research Turbine (SWRT).

\section{Overview of FAST}

Before describing FAST's new furling capability, it is constructive to step back and outline the general class of modeling techniques employed in FAST. For a more detailed description of these methodologies, see the FAST User's Guide ${ }^{1}$.

FAST models the blades and tower as individual flexible elements using a modal representation. The flexibility characteristics of these members are determined by specifying distributed stiffness and mass properties along the span of the members and by prescribing their mode shapes through equivalent polynomial coefficients. FAST has two flapwise and one edgewise bending mode per blade and two fore-aft and two side-to-side bending modes in the tower. Torsional flexibility in the drivetrain is modeled using an equivalent linear spring and damper model in the low-speed shaft. The nacelle and hub are modeled in FAST as rigid bodies with appropriate mass and inertia terms. Time marching of the equations of motion is performed using a constant-time-step, Adams-Bashforth-AdamsMoulton, predictor-corrector integration scheme. FAST has a limited number of degrees-of-freedom (DOFs) but can model most common wind turbine configurations and control scenarios. These DOFs can be enabled or locked through switches, permitting the user to easily increase or decrease the fidelity of the model.

FAST can extract linearized representations of the complete nonlinear aeroelastic wind turbine model. This analysis capability is useful for developing state matrices of a wind turbine "plant" to aid in controls design and analysis. It is also useful for determining the full system modes of an operating or stationary HAWT through the use of a simple eigenanalysis.

Another feature available in FAST is the ADAMS preprocessor. The FAST-to-ADAMS preprocessor uses the configuration information available in the FAST input files to construct an ADAMS dataset (model) of the complete aeroelastic wind turbine.

Both FAST and ADAMS use the AeroDyn aerodynamic subroutine package for computing aerodynamic forces ${ }^{4}$. This aerodynamic package models rotor aerodynamics using the classic, equilibrium-based, bladeelement/momentum (BEM) theory or by using a generalized dynamic inflow model, both of which include the effects of axial and tangential induction. The BEM model uses tip and hub losses as characterized by Prandtl. Dynamic-stall behavior can be characterized using the optional Beddoes-Leishman dynamic stall model. More details can be found in the AeroDyn theory manual.

\section{Furling Capability Upgrades}

The recent upgrades to FAST feature a lateral thrust offset and skew angle of the rotor shaft from the yaw axis, rotor- and tail-furling DOFs, up- and down-furl stops and tail fin aerodynamics and inertia.

The location and orientation of the new furling DOFs are user-specified, making the simulator flexible enough to model many furling wind turbine configurations. For example, to model a wind turbine with tailfurling, the new tail-furl DOF should be enabled and the rotor-furl DOF locked. The angular motion of the tail boom and fin through the tail-furl DOF then takes place about a tail-furl axis defined by input parameters TFrlPntxn, TFrlPntyn, TFrlPntzn, TFrlSkew and TFrlTilt. Inputs TFrlPntxn, TFrIPntyn and TFrlPntzn locate an arbitrary point on the tail-furl axis relative to the tower-top. Inputs TFrlSkew and TFrITilt then define the angular orientation of the tail-furl axis passing through this point. See Fig. 3 for a schematic. A similar set of input parameters is used to define

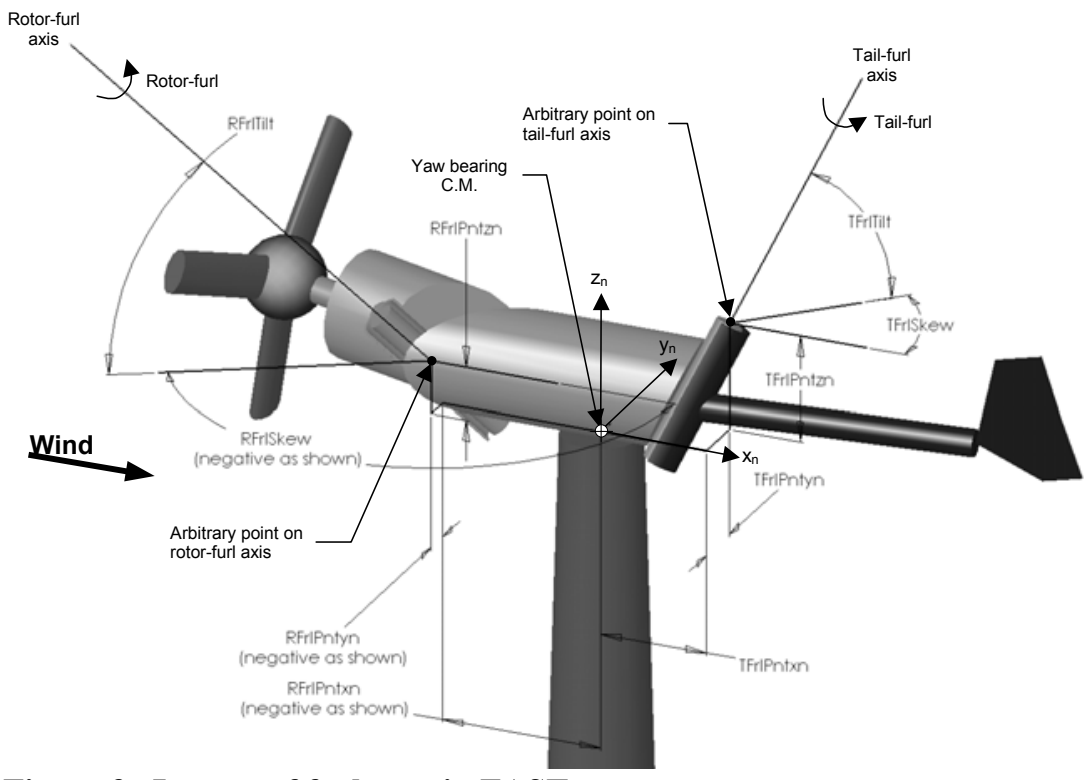

Figure 3. Layout of furl axes in FAST. 
the rotor-furl DOF for a turbine with rotor-furling (such a turbine should have the tail-furl DOF locked). The rotor-furl DOF can alternatively be used to model torsional flexibility in the gearbox mounting if the rotor-furl axis is aligned with the rotor shaft axis.

The structural dynamic equations of motion of the full system now include all of the inertia forces (gyroscopic, Coriolis, etc.) that result from furl motion. These equations do not require that the furl motions remain small because small angle assumptions were not used in their derivations. A FAST user does not need to worry about the complexity of the equations of motion because they are built within the code; a user need only be concerned with defining the

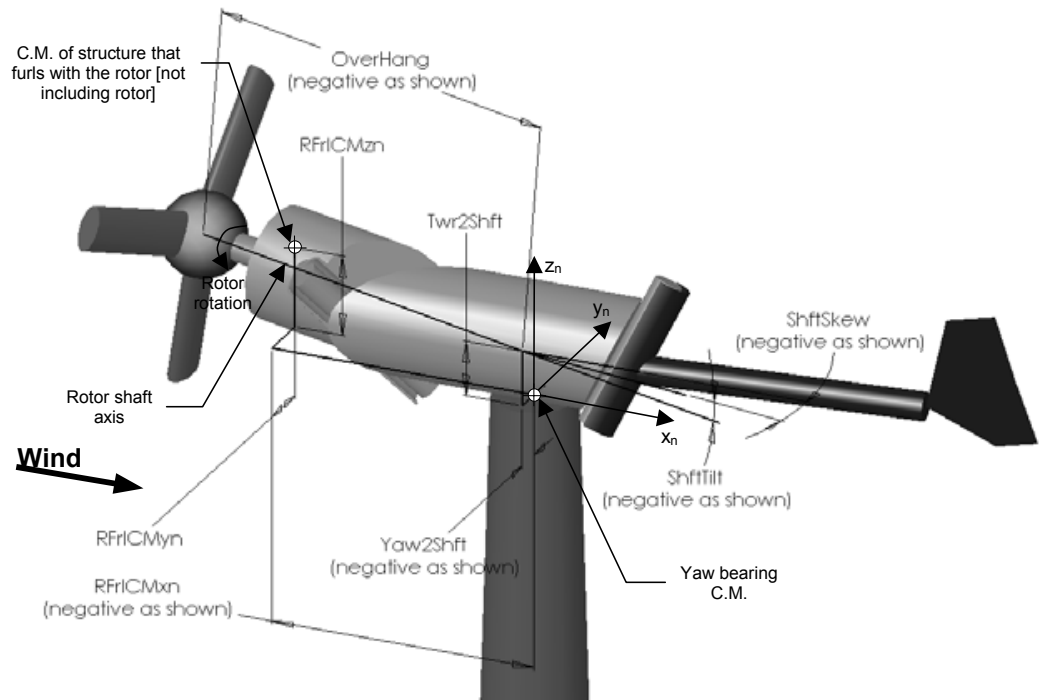

Figure 4. Rotor-furling mass and configuration properties in FAST. configuration of the system properly. Figure 4 and Fig. 5 illustrate the input parameters that define the configuration of the rotor-furling and tail-furling components, respectively. As implied by these figures, the generator housing is modeled as a rigid body with a lumped point mass and a moment of inertia specified about the rotor-furl axis. The tail is modeled as a rigid body with lumped tail boom and tail fin point masses and a moment of inertia specified about the tail-furl axis.

The furling hinges can be ideal with no friction. A standard model is also available that includes a linear spring, linear damper and Coulomb damper, as well as up- and down-stop springs and up- and down-stop dampers. FAST models the stop springs with a linear function of furl deflection. The furl stops start at a specified angle and work as a linear spring based on the deflection past the stop angle. The furl dampers are linear functions of the furl rate and start at the specified up-stop and down-stop angles. These dampers are bidirectional, resisting motion equally in both directions once they pass the stop angle. Hooks for interfacing user-defined furl springs and dampers are also available.

The AeroDyn rotor aerodynamics, which already accounted for skewed flow, were not modified for the addition of furling capability. However, a simple tail fin aerodynamics model has been implemented in FAST. Hooks for interfacing user-defined models are also available. By accessing information from AeroDyn, the simple model

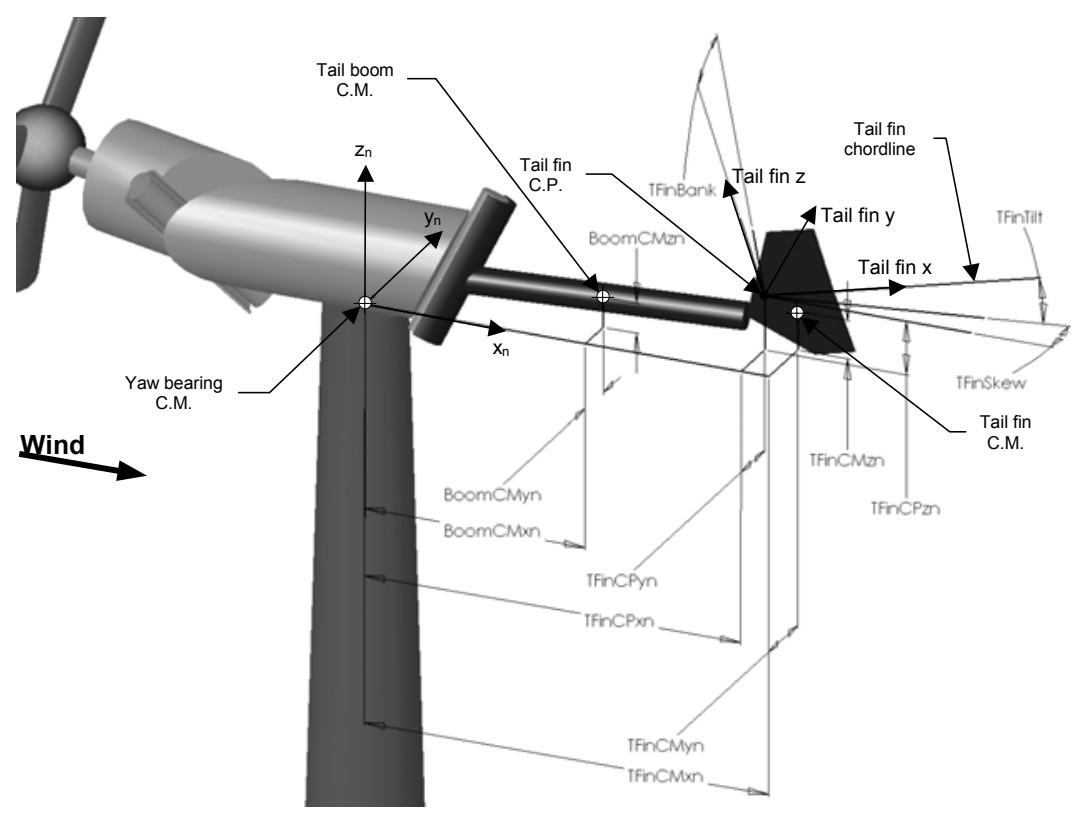
computes the relative velocity of the wind-inflow and its angle of attack relative to the tail fin chordline and uses an AeroDyn airfoil table chosen by the user to determine the lift and drag forces acting at the tail fin center-of-pressure. To account for the velocity deficit in the rotor wake, the wind velocity at the tail fin center-ofpressure is decreased by the average rotor induced velocity in the direction of the rotor shaft. The chordline and plane of the tail fin may be skewed, tilted and banked relative to the tail boom as shown in Fig. 5.

The linearization features of FAST have been extended so that the resulting linearized models can now contain furling DOF "states," which produce furling modes.

Figure 5. Tail-furling mass and configuration properties in FAST. 
The FAST-to-ADAMS preprocessor has also been upgraded so that FAST can create an ADAMS dataset of a furling wind turbine by making use of the input parameters that specify the furling configuration. Graphic elements of the tail boom and tail fin are included in the ADAMS dataset.

\section{SWRT Test and Simulation Models}

To verify the correct implementation of the newly added furling dynamics, response predictions from FAST were compared to those of ADAMS using models of the SWRT. For validation of the SWRT model and of FAST's furling predictions, comparisons were made to test data.

The real SWRT (Fig. 6) is a highly instrumented and extensively modified Bergey Excel $10 \mathrm{~kW}$ system. The rotor furls horizontally out of the wind by means of a tail-furling hinge, which includes up- and downfurl stops and a furl damper. The SWRT testing campaign has provided detailed measurements of furling behavior and loads data that were previously unavailable. All tests were run in the field over a

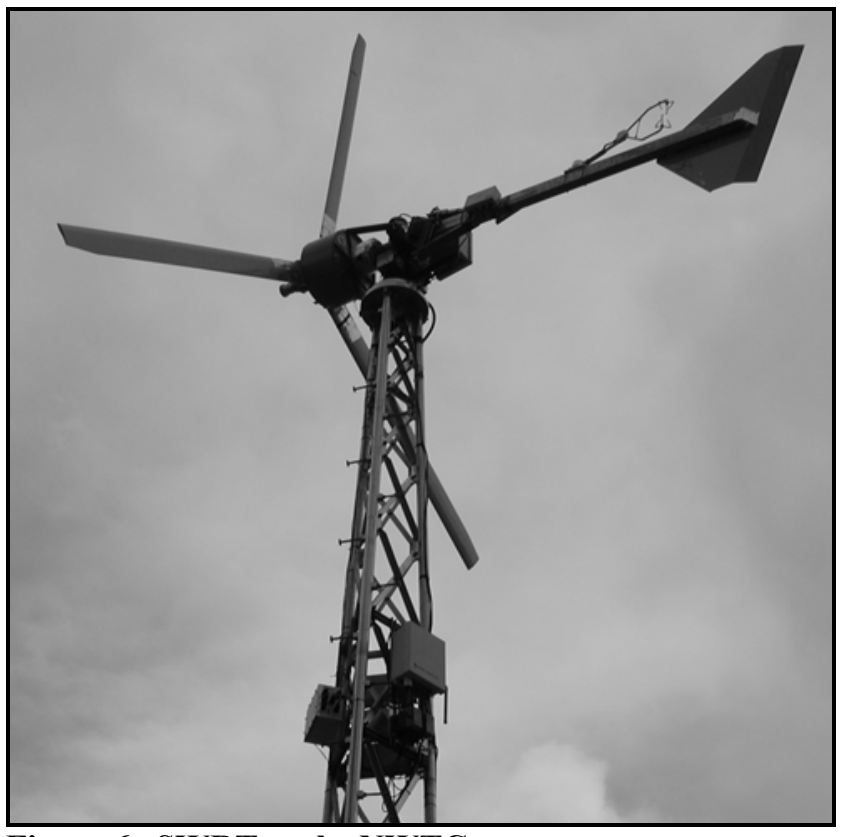

Figure 6. SWRT at the NWTC. course of one year at the NWTC. More details on the turbine and test methods are provided in a companion paper at this conference ${ }^{5}$.

The FAST model of the SWRT was developed using geometric, aerodynamic and mass properties measured at the NWTC or provided by Bergey Windpower. The model includes blade flexibility, a variable speed generator with a torque-speed look-up table, tail-furling with nonlinear user-defined springs and dampers and free yaw.

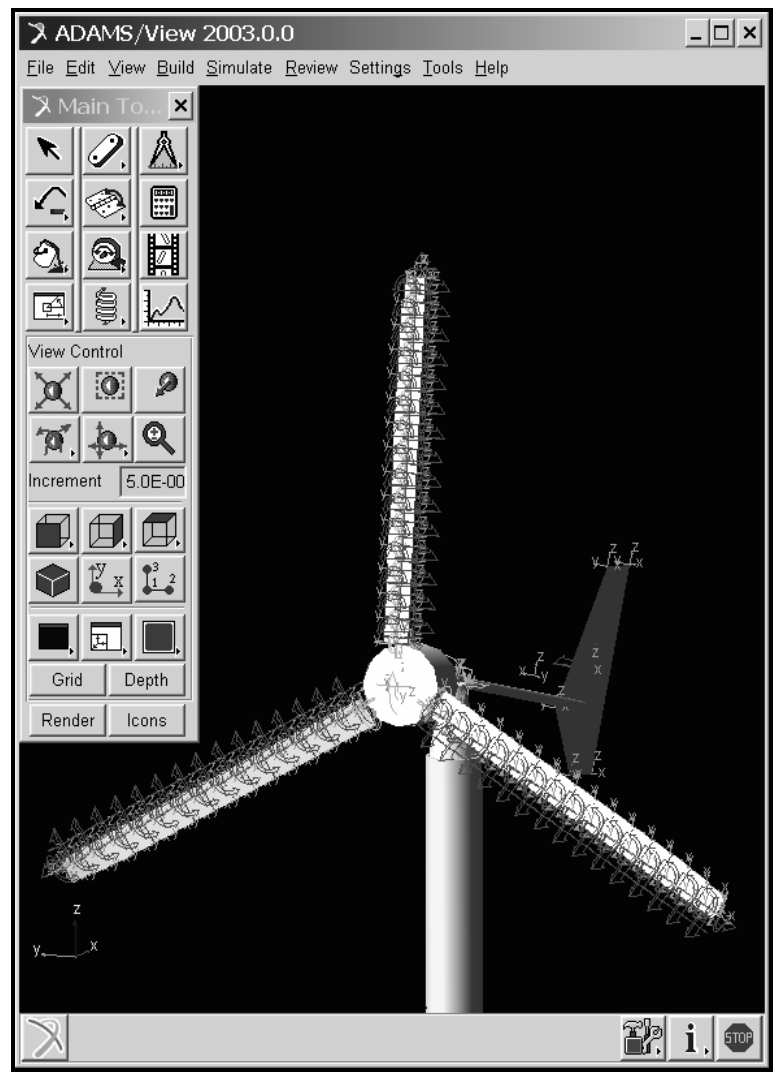

Figure 7. ADAMS SWRT model generated by FAST.

\section{Verification of Furling Dynamics}

It is advantageous to verify FAST's furling dynamics against ADAMS because the dynamics in ADAMS are not defined by the user and are well verified. FAST's dynamic response predictions for turbines without furling have been well verified against ADAMS in a previous study.

For our recent comparisons to ADAMS, we used FAST v5.10d-jmj, AeroDyn v12.56 and ADAMS 2003.0.0. We generated our ADAMS dataset (Fig. 7) using the FAST-toADAMS preprocessing capability of FAST. We used SNwind v1.22 to generate full-field turbulent wind files for some of the test cases and IECWind v4.21 to generate extreme wind conditions for others.

Because of the space limitations for this paper, we cannot describe the verification tests in any detail; we will only describe the results.

In general, the comparisons of response predictions between the codes show excellent agreement. In most output channels, the FAST and ADAMS response predictions agree so well that the ADAMS curve cannot be distinguished from the FAST curve. For example, Fig. 8 shows predictions of the tail-furl and yaw angle responses to a one-year extreme operating gust in IEC category A conditions. The slight variations that do exist are attributed to the higher-fidelity blade flexibility model in ADAMS that accounts for blade torsion and higher-order bending modes. Comparisons like these demonstrate that FAST's 


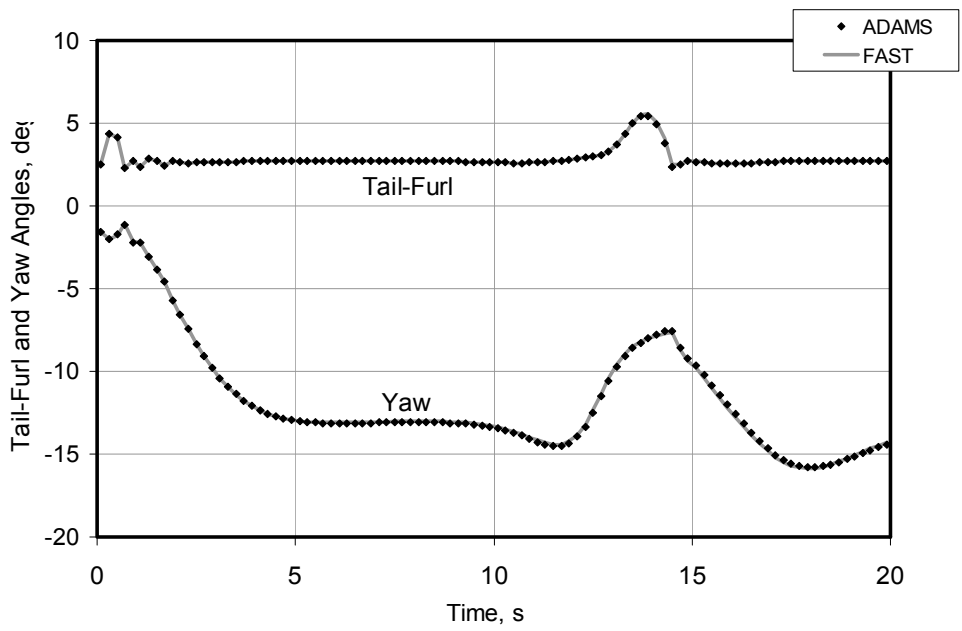

Figure 8. Tail-furl and yaw angle response during a one-year extreme operating gust.

future work.

All model results shown in this section were generated with FAST v5.10d-jmj. Two types of comparisons will be shown. Direct comparison of time series is useful in that it provides a highly detailed view of a small amount of data. Comparisons of summary statistics are valuable because they provide a view of a large quantity of data, albeit in much less detail.

Time series comparisons are made by driving the FAST model with measured wind data. In these cases, we had measurements of the hub-height horizontal and vertical wind speeds and the wind direction. We did not have measurements of instantaneous horizontal wind shear. Horizontal wind shear is known to be an important driver of yaw and furling motions, but it is difficult to measure. Driving a model with such "hub-height" wind data misses small-scale turbulence effects, but captures the large-scale, slow variations in wind characteristics.

Comparisons of statistics are accomplished by running the FAST model with simulated turbulent wind conditions generated by SNWind v1.22. We used an $8 \times 8$ grid of points across the rotor disc and generated three components of time-varying wind at each grid point. In the present work, we generated turbulence with statistics that match the IEC category A conditions ${ }^{10}$. It would be preferable from a technical point of view to generate turbulence with statistics that match each of the test records. Unfortunately, the cost and time required to generate 186 turbulence files that match three components of turbulence intensity and length scale of the measurements made this option impractical.

Figures 9 and 10 compare measured and predicted rotor speed and furl angle for 10-minutes of operation of configuration A with an inverter load. The mean wind speed during this test was $14.1 \mathrm{~m} / \mathrm{s}$. Two sets of predictions are shown. The first predictions were made with no "tuning" of model inputs to improve the match (though measured turbine properties such as blade natural frequencies and masses were used to develop the model). The second predictions were made after the airfoil data tables were modified to improve

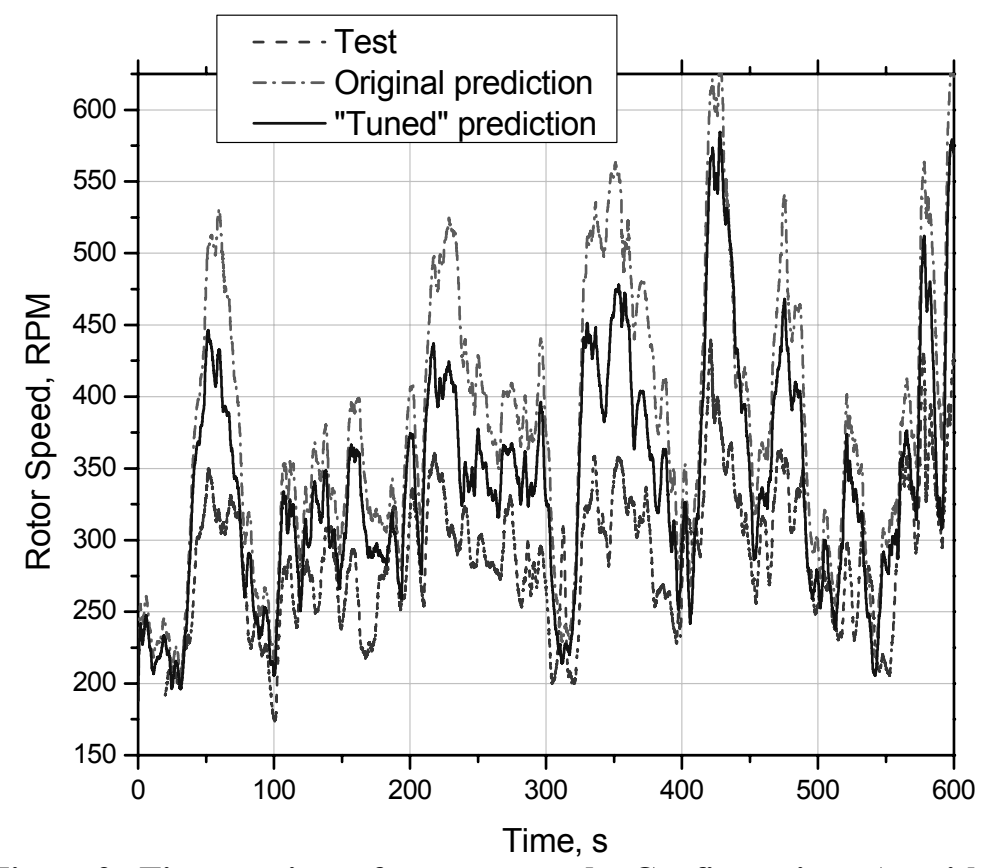

Figure 9. Time series of rotor speed. Configuration A with inverter load. 
agreement between measured and predicted power coefficients. The lift coefficients were reduced and the drag increased to reduce the power output of the rotor. This tuning process is highly uncertain and could be the subject of another paper. There is not enough space in this paper to provide more details on the tuning that was done.

Figures 9 and 10 show that the model correctly predicts the general behavior of the rotor but significantly over-predicts the rotor speed. The rotor speed prediction improved after the airfoil tables were modified, but the predictions remain higher than the data. At times, the furl angle is accurately predicted, but there are many other times when the furl angle is over- or under-predicted. These observations are consistent with prior experience modeling and testing a Whisper $\mathrm{H} 40$ furling turbine.

Though not shown in any of the following figures, the FAST model significantly under-predicts root edge bending moments in high rotor speeds, while rotor

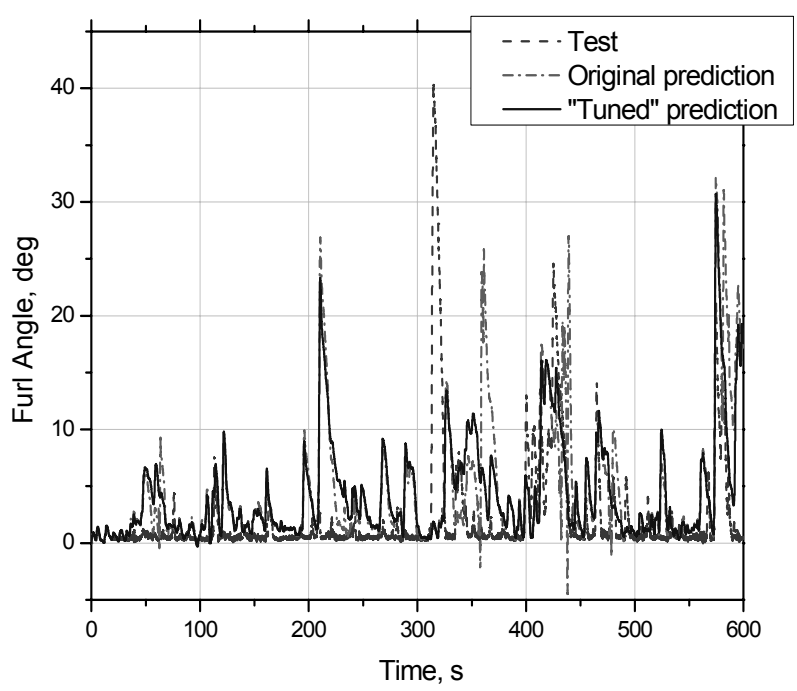
torque is predicted reasonably well. It was discovered that the cause of this discrepancy is chordwise mass offsets combined with increasing centrifugal forces in high rotor speeds. (The real SWRT has chordwise mass offsets that the FAST model does not account for.) The chordwise mass offset generates no centrifugal moment about the axis of rotation; hence it has no effect on the rotor torque. It does, however, generate an edgewise moment at any blade station that is not on the rotor axis. See Ref. 5 for more information on this phenomenon.

Figures 11 through 15 compare statistics for 186 10-minute test records and 40 10-minute simulations. All of these results are for configuration A with an inverter load. All of these and subsequent predictions use the modified airfoil tables. Figure 11 compares the measured turbulence intensities with the values generated by SNWind and used in the FAST predictions. There is much more variation in measured turbulence than in the turbulence used in the FAST code. This inevitably produces more variations in the measured turbine response than in the predicted response.

The trends are quite interesting. Mean rotor speed is over-predicted in winds above $12 \mathrm{~m} / \mathrm{s}$, but maximum rotor speed is under-predicted except in winds above approximately $14 \mathrm{~m} / \mathrm{s}$. Mean furl angle and rotor thrust predictions are in very good agreement with the data. Although there is quite a bit of scatter in the peak values, the model and test results are similar for furl angle. The peak rotor

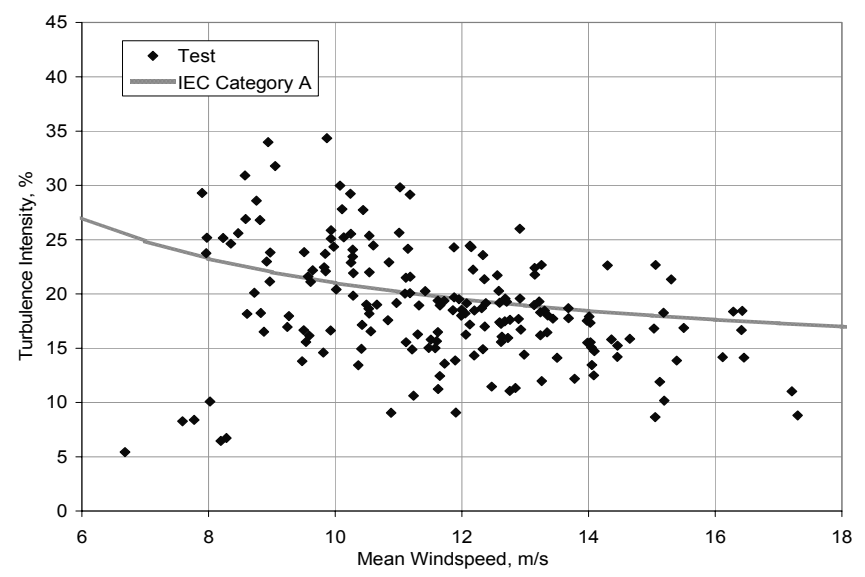

Figure 11. Measured and IEC " $A$ " turbulence intensities. Configuration A with inverter load.

thrust predictions are consistently lower than the data. Mean yaw error is under-predicted by approximately $5^{\circ}$ to $10^{\circ}$ as shown in Fig. 15. Maximum yaw error, due to the rapid fluctuations in wind direction, contains tremendous scatter and is not shown.

The results seem to indicate that the lift forces on the blades are predicted with reasonable accuracy, hence the good prediction of rotor thrust and furl angle. An error in drag prediction on the blades could account for the error in rotor speed prediction without causing errors in the thrust prediction. It is also possible that compressibility effects are becoming important at the high rotor speeds of these tests. The Mach number at the blade tip is approximately 0.45 at 500 RPM and 0.62 at 700 RPM. Unfortunately, there are too many variables involved in the furling prediction to allow us to determine, with confidence, what the dominant source of error might be. 


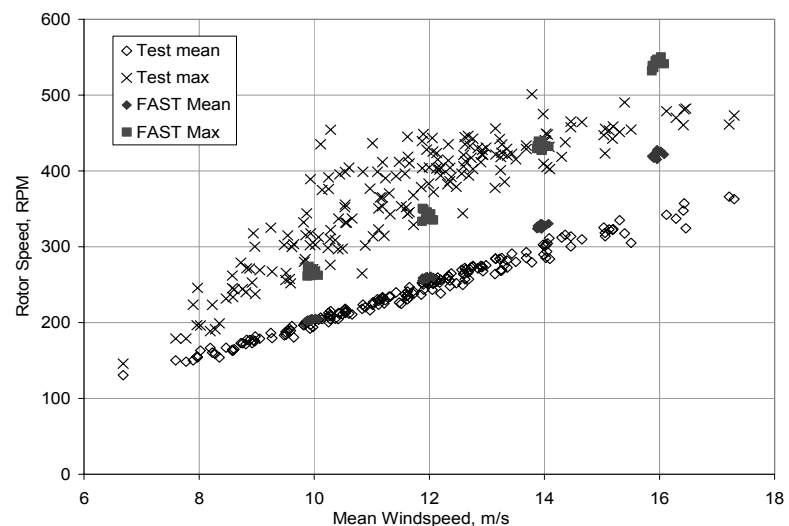

Figure 12. 10-minute mean and maximum values of rotor speed. Configuration A with inverter load.

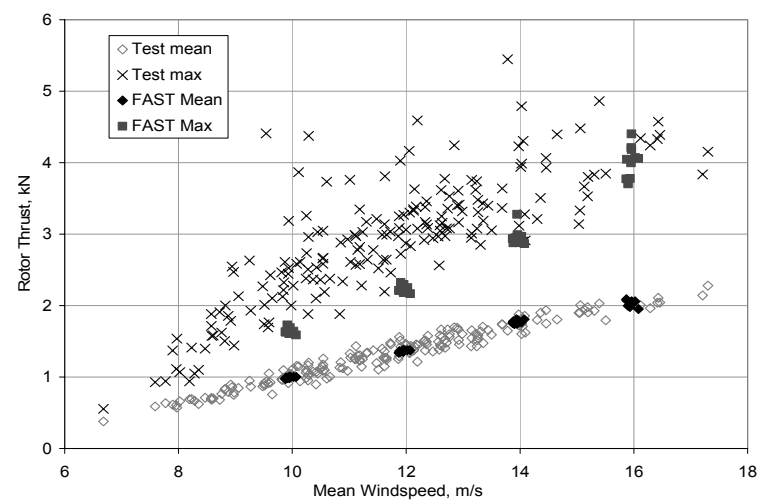

Figure 14. Statistics of rotor thrust for the same tests and predictions of Fig. 12.

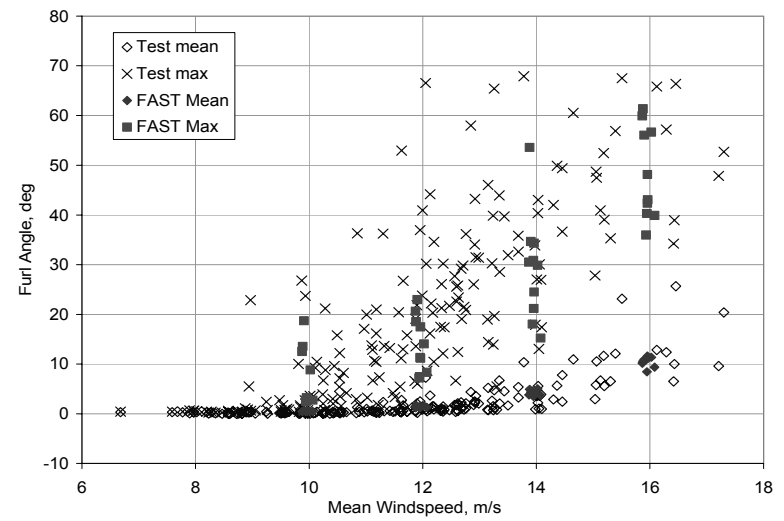

Figure 13. Statistics of tail-furl angle for the same tests and predictions of Fig. 12.

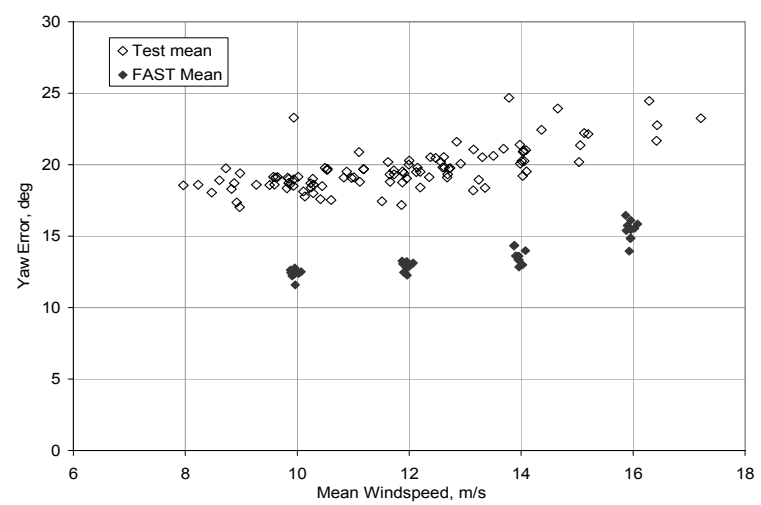

Figure 15. Mean yaw error for the same tests and predictions of Fig. 12.

Figures 16 through 19 show similar results for configuration B with an inverter load. There are 47 test data sets and 40 simulations represented in these plots. The trends are very similar to those shown for configuration A though, as expected, the reduced thrust offset results in less furling. However, the reduced rotor offset does not significantly change the rotor speeds. Note that the mean furl angle is accurately predicted but, unlike configuration A, the peak furl angles are generally over-predicted.

Finally, time series comparisons were done for configuration B operating with a resistor load. This load changes the alternator torque-speed curve and makes it more consistent (the inverter was constantly changing the load on the alternator, introducing a random element in the torque-speed curve that our models do not account for). The average wind during this 10 -minute test was $17.6 \mathrm{~m} / \mathrm{s}$, which produced considerable furl motion.

Figures 20 through 23 show some of the results with more detail but point to the same general conclusions. Rotor speed predictions are consistently too high while furl, thrust and yaw predictions are quite accurate.

Figure 24 presents the furl and thrust results of Fig. 21 and Fig. 22 in a different format. The results were smoothed using a 1-second moving average to reduce the scatter in the plot. The model and data trends are quite different when viewed in this manner. Note that, while the model peak thrust is higher, there is less furling. This indicates a possible problem in the model inputs, perhaps in the nonlinear furl damper, which provides little resistance to furling but high resistance to unfurling. This behavior is included in the model, but there is some uncertainty regarding the characteristics. The lack of instantaneous wind shears in the model winds is another likely contributor to this discrepancy. Of course, it may also indicate a more fundamental problem with the aerodynamic model of the rotor or tail fin. As mentioned before, there are too many variables to be confident of finding the major sources of model errors. 


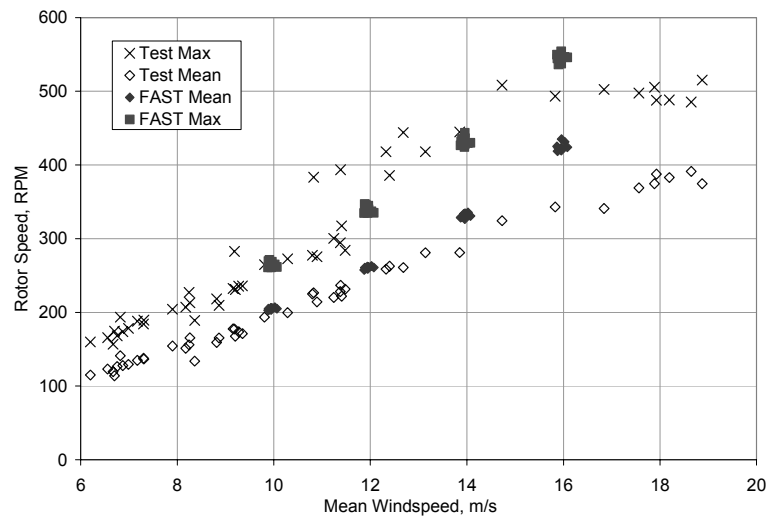

Figure 16. 10-minute mean and maximum values of rotor speed. Configuration B with inverter load.

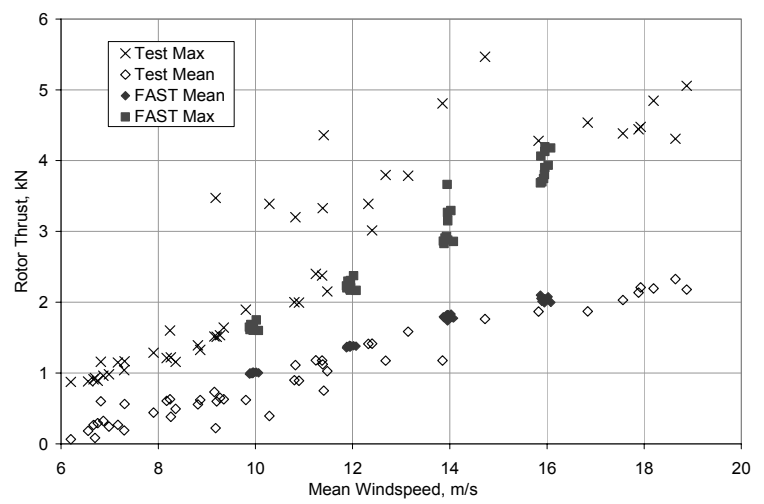

Figure 18. Statistics of rotor thrust for the same tests and predictions of Fig. 16.

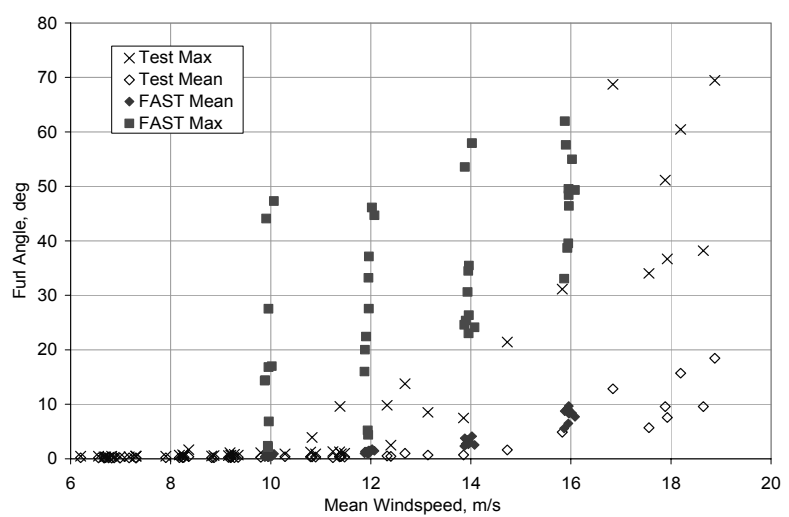

Figure 17. Statistics of tail-furl angle for the same tests and predictions of Fig. 16.

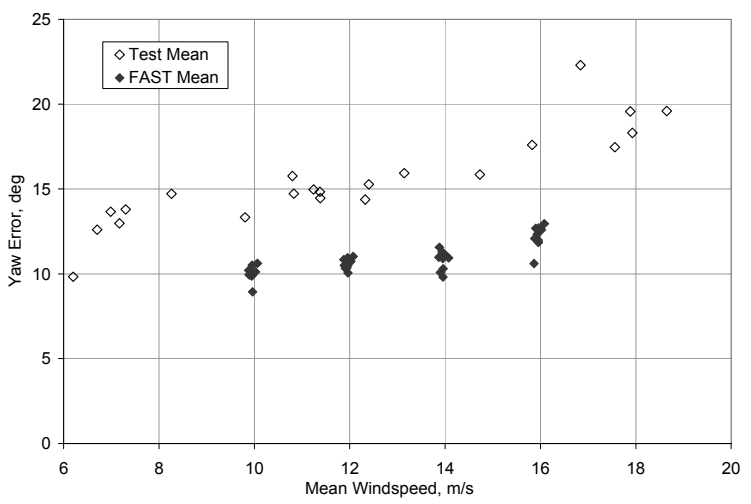

Figure 19. Statistics of yaw error for the same tests and predictions of Fig 16.

\section{Conclusion}

The need for a wind turbine simulator with furling capability that is simpler to use and more readily available led NREL to upgrade their FAST aeroelastic simulator. The features in the upgrade include a lateral offset and skew angle of the rotor shaft, rotor- and tail-furling DOFs, up- and down-furl stops and tail fin aerodynamics and inertia.

A verification study demonstrated the correct implementation of the newly added furling dynamics by comparing response predictions from FAST and ADAMS.

As in previous code validation efforts ${ }^{13,14}$, we see areas of broad agreement between model and test results. We also see important areas of disagreement. The model tends to predict mean rotor speeds higher than measured in spite of the fact that the mean furl motion and rotor thrust are predicted quite accurately. Peak values show larger discrepancies than mean values. This is expected in the very turbulent winds of the NWTC test site, but it probably also indicates that nonlinearities in the system are not modeled with sufficient accuracy. Examples of important nonlinearities in the SWRT turbine are the mechanical furl damper and, of course, the unsteady aerodynamics of a rotor with a skewed and turbulent inflow.

Experience with design and research projects has shown us that computer models can be very helpful during the design and optimization of furling behavior. They have successfully pointed out counter-intuitive design changes that have shortened the design/test/iterate cycle. The current and earlier projects have also clearly pointed out the need to improve our understanding of furling behavior and its representation in our computer models.

\section{Future Work}

The NWTC is planning to incorporate additional DOFs and functionality to FAST in the near future. We plan to add a torsion DOF to the modal representation of the tower and to extend the modal representation of the blades to include mass and elastic offsets, torsion DOFs and coupled mode shape properties. In addition, we plan to introduce 


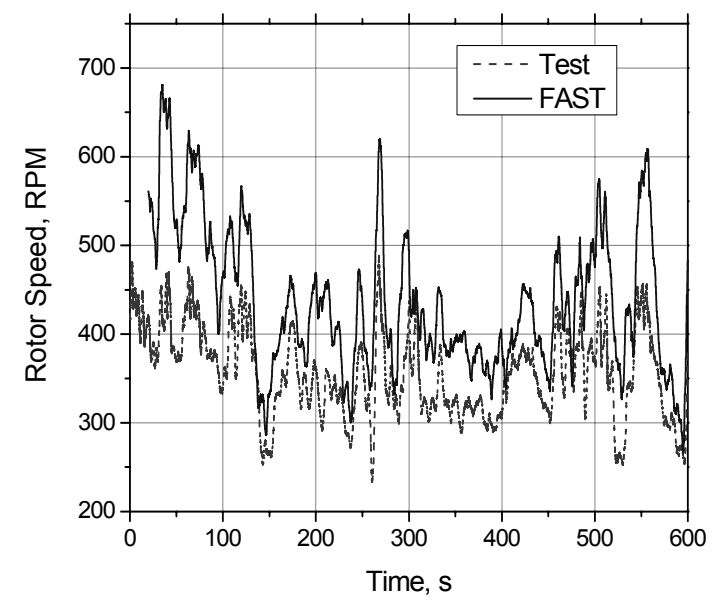

Figure 20. Rotor speed during one 10-minute test of Configuration $B$ with resistor load.

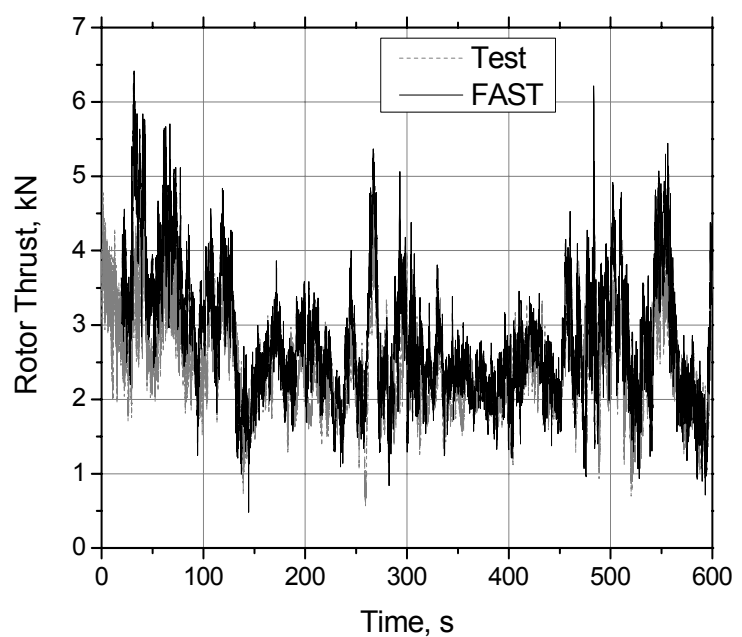

Figure 22. Rotor thrust during the same test shown in Fig. 20.

a variable step size integrator into FAST to eradicate the numerical difficulties involved in modeling rapidly changing rotor speeds and/or highly nonlinear user-defined springs and dampers. Both of these code enhancements should help improve the accuracy of dynamic response predictions of furling wind turbines.

Additional code enhancements not relating to furling behavior are planned for FAST. The most important include plans to add six support-platform motion DOFs (three translation, three rotation), foundation flexibility and earthquake loading models and wave loading dynamics. Two orthogonal drivetrain shaft-bending DOFs will also be added so that users can predict the important dynamics associated with the whirl of the shaft.

As the code becomes more complex, the NWTC will complete additional verification studies. One such study is already in the works as FAST and ADAMS are being tested

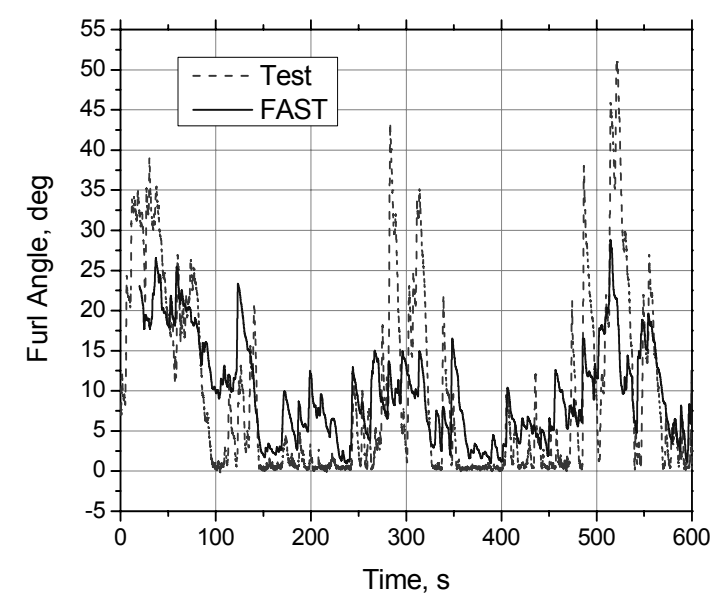

Figure 21. Tail-furl angle during the same test shown in Fig. 20.

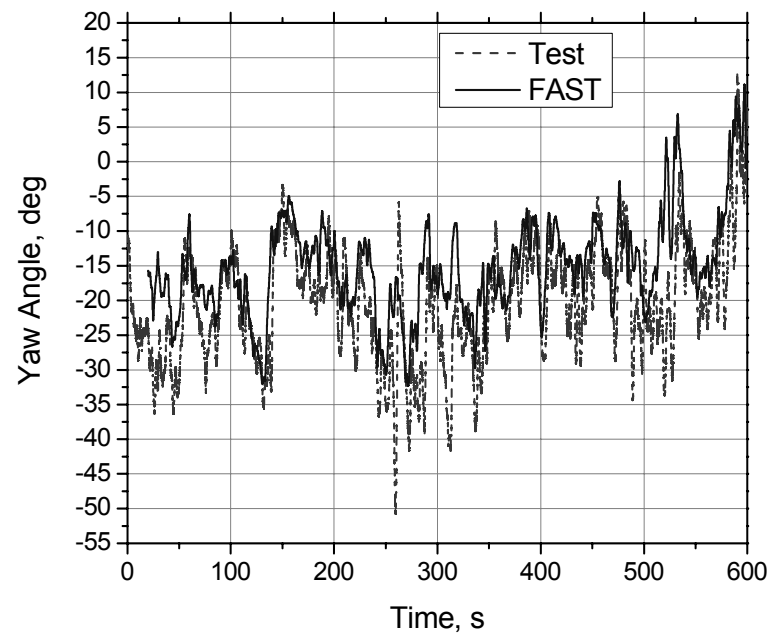

Figure 23. Rotor yaw angle during the same test shown in Fig. 20.

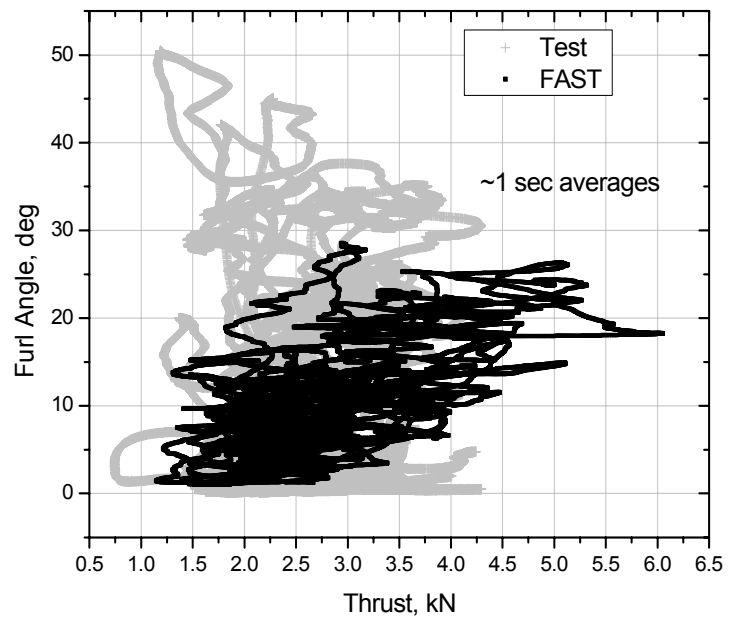

Figure 24. Scatterplots of 1-second average tailfurl angle versus rotor thrust for the same dataset of Fig. 20. 
by Germanischer Lloyd AG ${ }^{\dagger \dagger}$ (GL) in partnership with the NWTC.

We also plan to continue to exploit the data from the SWRT experiment to further validate and improve furling dynamics predictions. We have plans to continue the SWRT model validation using data from configuration $\mathrm{C}$ and to inspect and test output channels that have yet to be examined.

\section{Acknowledgments}

The authors would like to thank everyone who helped with this work, including the small wind turbine design community, for their invaluable feedback related to code functionality and usability considerations (especially the staff of Bergey Windpower, Southwest Windpower, Global Energy Concepts LLC, Windward Engineering LLC and NREL); Jason Cotrell of NREL, for helping create turbine layout schematics in SolidWorks; Jeff Minnema of Windward Engineering LLC, for assembling the first furling model in FAST and alpha-testing the new features; Dave Corbus, Dan Prascher and Mark Meadors of NREL, for providing us with SWRT data and Kathleen O'Dell of NREL, for making this paper much more readable.

This work was performed in support of the U.S. DOE by NREL under contract number DE-AC36-99-GO10337 and by Windward Engineering LLC under NREL subcontract number LAM-3-33216-01.

\section{References}

${ }^{1}$ Jonkman, J. M., and Buhl, M. L., Jr., "FAST User's Guide,” NREL/EL-500-29798, Golden, CO: National Renewable Energy Laboratory, October 2004.

${ }^{2}$ Laino, David J., and Hansen, A. Craig, "User's Guide to the Computer Software Routines AeroDyn Interface for ADAMS ${ }^{\circledR}, "$ Salt Lake City, UT: Windward Engineering LLC, Prepared for the National Renewable Energy Laboratory under Subcontract No. TCX-9-29209-01, September 2001.

${ }^{3}$ Elliott, A. S., “Analyzing Rotor Dynamics with a General-Purpose Code," Mechanical Engineering, Vol. 112, No. 12, December 1990, pp. 21-25.

${ }^{4}$ Laino, David J., and Hansen, A. Craig, "User's Guide to the Wind Turbine Dynamics Aerodynamics Computer Software AeroDyn," Salt Lake City, UT: Windward Engineering LLC, Prepared for the National Renewable Energy Laboratory under Subcontract No. TCX-9-29209-01, December 2002.

${ }^{5}$ Corbus, D., and Prascher, D., "Analysis and Comparison of Test Results from the Small Wind Research Turbine Test

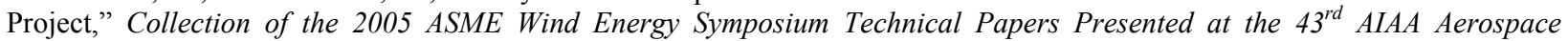
Sciences Meeting and Exhibit, 10-13 January 2005, Reno, NV, Washington, D.C.: American Institute of Aeronautics and Astronautics, January 2005, NREL/CP-500-36891.

${ }^{6}$ Moriarty, Patrick J., and Hansen, A. Craig, “AeroDyn Theory Manual," NREL/EL-500-36881, Golden, CO: National Renewable Energy Laboratory, October 2004.

${ }^{7} J o n k m a n$, J. M., and Buhl, M. L., Jr., "New Developments for the NWTC's FAST Aeroelastic HAWT Simulator," Collection of the 2004 ASME Wind Energy Symposium Technical Papers Presented at the $42^{\text {nd }}$ AIAA Aerospace Sciences Meeting and Exhibit, 5-8 January 2004, Reno, NV, Washington, D.C.: American Institute of Aeronautics and Astronautics, January 2004, pp. 181-191; NREL/CP-500-35077.

${ }^{8}$ Buhl, M. L., Jr., "SNwind User's Guide," NREL/EL-500-30121, Golden, CO: National Renewable Energy Laboratory, June 2003.

${ }^{9}$ IECWind, Software Package, Ver 4.21, Golden, CO: National Renewable Energy Laboratory, November 2002.

${ }^{10}$ IEC 61400-1, Wind Turbine Generator Systems - Part 1: Safety Requirements, $2^{\text {nd }}$ ed., International Electrotechnical Commission (IEC), 1999.

${ }^{11}$ Hansen, A. C., "Yaw Dynamics of Horizontal Axis Wind Turbines, Final Report," NREL/TP-442-4822, Golden, CO: National Renewable Energy Laboratory, May 1992.

${ }^{12}$ Davis, Dean A., Hansen, A. Craig, and Laino, David J., "Estimates of Maximum Design Loads for a Whisper H40 Using Extrapolation Methods," Proceedings of the Windpower 2003 Conference, 18-21 May 2003, Austin, TX, Washington, D.C.: American Wind Energy Association, session 4C, 2003.

${ }^{13}$ Eggers, A. J. Jr., Chaney, K., Holly, W. E., Ashley, Holt, Green, H. James, and Sencenbaugh, Jim, "Modeling of Yawing and Furling Behavior of Small Wind Turbines," Collection of the 2000 ASME Wind Energy Symposium Technical Papers Presented at the $38^{\text {th }}$ AIAA Aerospace Sciences Meeting and Exhibit, 10-13 January 2000, Reno, NV, Washington, D.C.: American Institute of Aeronautics and Astronautics, January 2000, pp. 1-11.

${ }^{14}$ Schreck, Scott (Editor), "Special Issue: Analysis and Modeling of the NREL Full-Scale Wind Tunnel Experiment," Wind Energy, Vol. 5, No. 2-3, April-September 2002.

†† Website: http://www.gl-group.com/start.htm. 


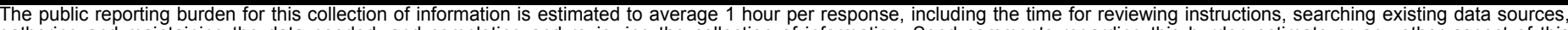

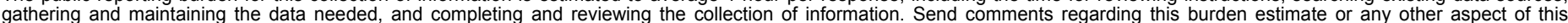

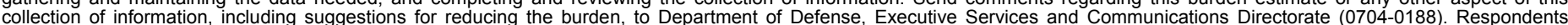

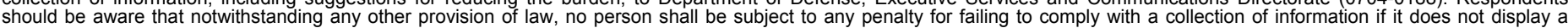

should be aware that notwithstanding

PLEASE DO NOT RETURN YOUR FORM TO THE ABOVE ORGANIZATION.

\begin{tabular}{l|l|l|l} 
1. REPORT DATE $(D D-M M-Y Y Y Y)$ & 2. REPORT TYPE & 3. DATES COVERED (FrOm - TO)
\end{tabular}

December 2004

Conference Paper

4. TITLE AND SUBTITLE

Development and Validation of an Aeroelastic Model of a Small

Furling Wind Turbine: Preprint 5a. CONTRACT NUMBER

DE-AC36-99-G010337

5b. GRANT NUMBER

5c. PROGRAM ELEMENT NUMBER

5d. PROJECT NUMBER

NREL/CP-500-39589

5e. TASK NUMBER

WER4.3102

5f. WORK UNIT NUMBER
7. PERFORMING ORGANIZATION NAME(S) AND ADDRESS(ES)

National Renewable Energy Laboratory

1617 Cole Blvd.

Golden, CO 80401-3393

9. SPONSORING/MONITORING AGENCY NAME(S) AND ADDRESS(ES)

\section{PERFORMING ORGANIZATION REPORT NUMBER}

NREL/CP-500-39589
10. SPONSOR/MONITOR'S ACRONYM(S) NREL

11. SPONSORING/MONITORING AGENCY REPORT NUMBER

12. DISTRIBUTION AVAILABILITY STATEMENT

National Technical Information Service

U.S. Department of Commerce

5285 Port Royal Road

Springfield, VA 22161

13. SUPPLEMENTARY NOTES

14. ABSTRACT (Maximum 200 Words)

Small wind turbines often use some form of furling (yawing and/or tilting out of the wind) to protect against excessive power generation and rotor speeds in high winds. The verification study demonstrated the correct implementation of FAST's furling dynamics. During validation, the model tends to predict mean rotor speeds higher than measured in spite of the fact that the mean furl motion and rotor thrust are predicted quite accurately. This work has culminated with an enhanced version of FAST that should prove to be a valuable asset to designers of small wind turbines.

15. SUBJECT TERMS

small wind turbine; modeling; furling; aeroelastic furling

\begin{tabular}{|c|c|c|}
\hline $\begin{array}{l}\text { a. REPORT } \\
\text { Unclassified }\end{array}$ & $\begin{array}{l}\text { b. ABSTRACT } \\
\text { Unclassified }\end{array}$ & $\begin{array}{l}\text { c. THIS PAGE } \\
\text { Unclassified }\end{array}$ \\
\hline
\end{tabular}

\begin{tabular}{l|l|} 
17. LIMITATION \\
OF ABSTRACT \\
UL
\end{tabular}

19a. NAME OF RESPONSIBLE PERSON

19b. TELEPONE NUMBER (Include area code) 